\title{
Formación inicial de profesorado, el papel de los tutores de prácticas
}

\section{Teachers' initial training: The role of school supervisors}

\section{Formação inicial de professores, o papel dos tutores de estágio supervisionado}

\author{
Abraham Bernárdez-Gómez ${ }^{1}$ \\ abraham.bernardez@um.es \\ Universidad de Murcia, España
}

\section{Resumen:}

La relación teoría-práctica y el comienzo de la vida laboral para los profesionales de la educación son aspectos de primer orden, donde las prácticas supervisadas adquieren un valor importante en su formación. Entre estos, los tutores de practicum juegan un papel fundamental, ya que son el primer contacto con profesionales activos. Por esta razón, este artículo tiene como objetivo identificar y explicar los roles que juegan los tutores de prácticas en la formación inicial del profesorado. Se llevará a cabo utilizando una metodología cualitativa que emplea entrevistas en profundidad, analizadas con el software ATLAS.ti. Se concluye la relevancia de los diferentes roles que emergen, destacando la importancia de tres de ellos para el desarrollo profesional de los estudiantes.

\section{Palabras clave:}

Formación inicial del profesorado; Practicum; Desarrollo profesional docente; Desarrollo de habilidades profesionales.

\begin{abstract}
:
The relationship between theory and practice and the beginning of a teaching career are aspects of utmost importance where supervised school-located placements are specially important. School supervisors during students' training periods are key since they are the first contact students have with active teachers. For this reason, this article aims to identify and explore the role of school supervisors in initial training. A qualitative methodology was used in which interviews were analyzed with the ATLAS.ti software. Results highlight the relevance of the different roles that emerge, especially three of them, when it comes to students' professional development.
\end{abstract}

\section{Key Words:}

Teachers' initial training; School-located training periods; Teachers' professional development; Development of professional skills.

1 Dirección para correspondencia (correspondence address):

Abraham Bernárdez-Gómez. Departamento de Didáctica y Organización Escolar. Facultad de Educación. Universidad de Murcia. Campus de Espinardo, s/n. 30100 Espinardo (España).

Ayudas a contratos predoctorales 2017 (REF: BES-2017-081040) 


\begin{abstract}
Resumo:
A relação teoria-prática e o início da vida laboral dos profissionais da educação são aspectos de extrema relevância, onde os estágios supervisionados adquirem um valor importante na sua formação. Entre estas, os tutores do estágio desempenham um papel fundamental, por ser o primeiro contato com profissionais ativos. Por esta razão, este artigo tem como objetivo identificar e explicar os papéis que os tutores do estágio desenvolvem na formação inicial de professores. Ele será conduzido usando uma metodologia qualitativa empregando entrevistas de profundidade, analisadas com o software de Atlas. ti. Conclui-se a relevância dos diferentes papéis que emergem, destacando-se a importância de três deles para o desenvolvimento profissional dos estudantes.
\end{abstract}

\title{
Palavras-chave:
}

Formação inicial de professores; Formação prática; Desenvolvimento profissional docente; Desenvolvimento das competências profissionais.

Fecha de recepción: 02-02-2020

Fecha de aceptación: 09-03-2020

\section{Introdução}

As novas realidades com que a educação deve ser vista são, em grande medida, uma forma de justificar as reformas que vêm acontecendo ao longo dos últimos anos, portanto, trata-se de uma ideia de transformação e consciência social que vai além das fronteiras nacionais, a fim de redefinir o papel dos professores e responder às necessidades de mudança (Gutierrez, Fernández e Rodriguez, 2014; Imbernón e Sabaté, 2018). O ensino, como fato profissional, requer treinamento de habilidades para realizar um serviço público.

O professor é aquele que se dedica a treinar os outros, ajudando no seu desenvolvimento humano e colaborando na implantação de todas as possibilidades do indivíduo e de sua integração ativa e responsável na vida social (Montero e Gewerc, 2018). Portanto, o ensino é uma profissão com sua própria identidade sujeita a um conjunto de saberes que compõem sua formação e a natureza da função docente. No entanto, o trabalho realizado pelos professores vai além daqueles que são considerados intrínsecos à profissão, incluindo outros além do estritamente pedagógico.

Graças a um grande número de autores (Alcalá, Garijo e Pueyo, 2017; Marchesi e Pérez, 2004; Marcelo e Valliant, 2009; Vaillant e Marcelo, 2015; Zabalza, 2013) podem ser extraídos traços característicos que são indispensáveis quando se pensa em formação de professores: implica en- 
sinar dentro e fora da atividade puramente curricular, se move em diferentes cenários, assume múltiplas dimensões em uma atividade profissional complexa ou a efemeridade de eventos que ocorrem na sala de aula. Assim, este artigo tem como objetivo identificar e explicar os papéis que os tutores do estágio desenvolvem na formação inicial de professores.

Dessa forma, a formação docente deve levar à aquisição e enriquecimento da competência profissional dos docentes envolvidos nas tarefas de capacitação, influenciando os elementos básicos do seu currículo formativo, que são o conhecimento, as habilidades e as competências, sendo a própria natureza do ensino, uma exigência para que os professores se engajem em sua formação e desenvolvimento profissional. "Uma vez que a concepção de professores e professoras como sujeitos ativos de sua formação, dificilmente pode ser outro o objetivo das diversas ações da formação que não a do desenvolvimento profissional daqueles que participam nela" (Montero, 2002, p. 70).

A formação de professores deve ser concebida como um continuum com uma estreita relação entre teoria e prática, integrando a formação de professores a partir de um ponto de vista conceitual, disciplinar e pedagógico (Escudero, Cutanda y Trillo, 2017; Montero, 2018). Desta forma, um currículo orientado para a prática da sala de aula alcança o sucesso quando o processo de ensino e aprendizagem é realizado através de um procedimento no qual os conhecimentos teórico e prático andam de mãos dadas.

\section{Marco Teórico}

\section{Tutoria de Practicum e tutoria em formação inicial}

O período de estágio é uma oportunidade de aprendizagem em um contexto diferente do que a Universidade, no qual você tem a possibilidade de refletir sobre o que você aprendeu e realizá-lo em um ambiente profissional, por isso não há dúvida sobre a importância da ação desenvolvida pelo tutor e a responsabilidade deste.

A maioria dos autores concorda que a tutoria é um processo que orienta o aluno a atingir seus objetivos e incorporar as habilidades necessárias para desempenhar seu trabalho como futuro professor. Especificamente, Jiménez (2006 em Hevia e González Riaño, 2012) define 
a tutoria como "o processo pelo qual uma pessoa experiente (tutor) ensina, aconselha e auxilia o estagiário em seu desenvolvimento pessoal e profissional, investindo tempo, energia e conhecimento". Por sua vez Zabalza e Cid (1998, p. 21) compreendem-no também, como "o processo da iniciação na profissão e para assegurar a conexão entre o discurso académico e a atividade profissional", daí a necessidade de relacionar a teoria e a prática, como mencionado anteriormente.

Assim, o conceito de tutoria propõe visões de grande interesse, como o vínculo que se estabelece entre tutor e estagiário, estabelecendo uma relação de ajuda durante o desenvolvimento da atividade profissional. Por sua vez, o tutor "é a primeira imagem do mundo profissional que o aluno recebe, constituindo uma referência educacional muito poderosa e efetiva que desempenha um papel fundamental na formação do aluno" (Puig, 2006 em Hevia e González Riaño, 2012). Sendo assim, este profissional esforça-se para compartilhar com o estudante situações educativas complexas que servem como práticas de referência e ferramentas de reflexão sobre a vida cotidiana da escola. Sendo, por sua vez, um detector das necessidades formativas do aprendiz, que pode propor formas de melhoria na formação deste.

Diferentes autores indicam que a tutoria na formação de professores é positiva para o desenvolvimento profissional e pessoal dos tutores. Isto, através da relação que se estabelece com o seu aluno e com a análise que ambos realizam no processo de aprendizagem, por meio da reflexão e da crítica de sua própria prática. Os alunos também são portadores de ideias e novas perspectivas que representam uma oportunidade que os tutores têm de conhecê-las e ser capaz de gerenciar suas habilidades comunicativas e de auto reflexão sobre elas e sua prática diária. Finalmente, a pesquisa aponta como os tutores se sentem "satisfeitos e orgulhosos" (Holmes, 1991; Martínez, 2006, em Pérez Abellás, Cid e Sarmiento, 2011) ao ver seus pontos de vista endossados pelos supervisores da Universidade, revitalizando seu entusiasmo pela educação e reencontro com a profissão.

No caso dos alunos destaca-se um grande apoio ao desenvolvimento profissional, sendo, muitas vezes, sua primeira experiência de trabalho, e assim, conseguindo sair do mundo acadêmico. A este respeito, Cid e Ocampo (2006) apontam como isso ajuda a aumentar a confiança e a auto-estima, melhorando assim a autorreflexão e a valorização pessoal. Talvez o aspecto mais marcante seja o apoio que esses alunos recebem, 
mostrando que a tutoria é um fator importante na profissionalização dos professores na formação. De acordo com Esteve (2006) existem três dimensões em torno das quais gira o apoio ao professor em formação:

- Dimensão formativa: que se baseia em oferecer aos alunos um treinamento teórico-prático sobre as habilidades que devem possuir como professores e dominar no final do estágio em que estão, como eles serão avaliados.

- Dimensão da incorporação na vida profissional: focada no apoio e tutoria de professores especialistas que orientam o trabalho dos professores na formação em seu primeiro contato com o mundo do trabalho.

- Dimensão controle e avaliação: graças ao qual será possível descobrir se o professor em formação adquiriu as habilidades necessárias para exercer com sucesso o ensino.

Portanto, durante esse período, prestamos grande atenção às atitudes e aptidões profissionais de cada indivíduo, observando, de forma precisa, não apenas aspectos conceituais, mas processuais e atitudinais, a partir dos quais pode-se reconstruir as funções que os tutores têm hoje.

Estas funções estão em consonância com as dimensões vistas e os benefícios que este período traz para os agentes de estágio acima mencionados. Apesar disso, em Zabalza e Cid (1998) e Domingo (2013) pode-se observar que, a investigação sobre as funções dos tutores não indica o mesmo de acordo com o autor que seguimos. Como pode-se ver na literatura, há uma série de aspectos que correspondem a todos os autores, ou pelo menos, em sua maioria. É o caso, dentro da dimensão formativa, de como os tutores têm a função de facilitar a aprendizagem, a aquisição de competências e estimulando a reflexão de seus alunos. Se falarmos sobre a dimensão da incorporação na vida profissional, podemos ver como o apoio e a ajuda ao futuro professor está no centro da atenção dos tutores, além disso, enfatiza aspectos como estabelecer relações de trabalho e escutar as necessidades e demandas dos alunos, dentro do espectro de funções a serem consideradas. Finalmente, dentro da dimensão controle encontramos todos os aspectos relacionados à valorização e gestão do período de prática, não esquecendo que deve ser feita a partir de um ponto de vista reflexivo.

As funções vistas até agora, deve-se anotar, concordam a uma extensão maior ou menor, com aquelas dispostas por Barrios et al. (1996, em 
Pérez Abellás et al. 2010, p. 43), que indica um perfil "ideal" que deve possuir o tutor de práticas em que muitas das funções observadas nos demais autores estão englobadas. Este profissional seria aquele que:

- Orienta o professor em formação, fornecendo-lhe a ajuda que ele ou ela exige.

- Observa, ajuda e aconselha.

- Facilita o conhecimento do centro e da linha pedagógica refletida no projeto educativo.

- O incentiva para que desenvolva um planejamento, análise e avaliação do trabalho que faz.

- O ajuda a observar e avaliar o trabalho dos alunos, dando progressivamente responsabilidades. Ajuda-o a preparar o trabalho e a avaliá-lo.

- Facilita a reflexão e a ação nas situações problemáticas que surgem na prática profissional para poder desenvolver um novo conceito de profissionalização.

- Incentiva a participação ativa.

- Cria novas necessidades para que o aluno desenvolva um conhecimento profundo da prática em si.

- Ajuda a investigar metodologias, facilitando a descoberta do modelo de desempenho ideal.

Como fomos capazes de verificar através da enumeração de todas as funções localizadas na bibliografia, o papel que o tutor exerce é marcado por uma série de características que deveriam acompanhar a todos. No entanto, veremos agora como múltiplas modalidades também são diferenciadas no desempenho do tutor.

\section{O tutor, papéis que ele desempenha.}

Até agora, temos nos aprofundado em diferentes aspectos relativos à formação inicial dos professores e do estágio como um dos seus segmentos curriculares relevantes. O presente trabalho, até agora, abordou sobre as práticas de formação de professores, a relação teoria-prática, a tutoria e as funções dos tutores, entre outros, mas não ajustamos uma definição para essa figura. Para isso, utilizaremos o que encontramos mais recorrente na literatura que define o tutor como:

A pessoa experiente que recebe o encargo de participar da formação 
e inserção no mercado de trabalho de um jovem aprendiz, proporcionando a orientação e apoio necessários e incentivado-lhe a fazer o trabalho da maneira que é mais positivo, tanto para ele e para aqueles que vão para ser afetados (Zabalza e Cid, 1998, p. 17 em Cid et al. 2011).

Como podemos inferir a partir da definição, haverá uma certa diversidade nos papéis do tutor. Por um lado, o vemos como um indivíduo que deve ajudar e colaborar para que outro se desenvolva, tanto no campo formativo como no profissional. Se considerarmos isso de outro aspecto, ele também pode se destacar como membro de uma equipe, já que não serão ele e seu aluno as únicas pessoas afetadas. Também, vamos ter em conta brevemente, como este processo implica realizar as gestões e planejamento adequados, por isso será um papel de interesse durante a formação do futuro professor. Da mesma forma, tendo em conta a literatura consultada, podemos destacar muitos mais papéis que este profissional da educação exerce, os quais serão estabelecidos por meio da conjugação das diferentes funções que os tutores realizam, gerando um papel de tutor ou de outros. Desta forma, um tutor que orienta o aluno nas práticas proporcionando-lhe o necessário, vai desempenhar um papel de conselheiro e apoio. E um que é limitado ao planejamento e ao desenvolvimento do estabelecido será um tutor gestor do estágio.

Todos estes modelos de tutor coincidem em maior ou menor extensão, porém o fator comum é que esses papéis se mostram no período do estágio. Tais papéis serão mais detalhados a seguir. Para isso foi escolhido o modelo de Pérez Abellás et al. (2010), uma vez que é entendido como o mais trabalhado no âmbito. Apesar disso, as páginas seguintes serão desenvolvidas de forma mais concisa.

\section{Como professor para imitar}

Este modelo de professor significa ser uma referência para os alunos durante a sua introdução no mundo do trabalho. Os tutores esperam que seus alunos atentem para o seu modo de fazer e agir e tomem-no como um modelo de boas práticas no exercício profissional. Pode-se dizer que se parece muito com a aprendizagem por imitação que é dada na infância, aprendendo os diferentes comportamentos por meio de observar e reproduzir o que foi internalizado no repertório pessoal de cada um.

Clarke et al. (2014) aponta esse tipo aprendizagem como uma das principais estratégias utilizadas no momento, na verdade ele nos diz que é o 
esperado pelos supervisores universitários. Desta forma, os alunos reproduzem o que aprenderam quando "experimentam" com sua própria classe "os professores cooperantes costumam tender para um modelo de aprendizado no qual os professores do estágio supervisionado observam e então ensinam e, em muitos casos, imitam sua prática ao começarem a experimentar com seu próprio ensino em sala de aula" (Clarke et al., 2014, p. 177).

\section{Como gerente do estágio}

Esse modelo de tutor está mais relacionado ao escopo de planejamento do estágio, gerenciando seu desenvolvimento e valorizando como é implementado no centro de prática. Para isso, os tutores devem realizar tarefas precisas do programa que, segundo Pérez Abellás et al. (2010), são subdivididos em duas grandes áreas. Por um lado, deve-se projetar um programa de capacitação para o aluno, por meio do qual definirá alguns objetivos, partindo de uma detecção de necessidades, e assim estabelecer um itinerário de ações para sua tutoria. Desta forma, deve saber estabelecer as diferentes fases pelas quais passará o período de prática, incluindo nelas as avaliações correspondentes do processo. Por outro lado, o tutor "gerente" implementará este programa no ambiente de trabalho onde ele vai ter lugar. Fazendo isso, integrando o recémchegado, organizando e responsabilizando-se de seu processo de treinamento. Em suma, irá realizar o previsto no primeiro âmbito de atuação.

\section{Como conselheiro e apoio do aluno de estágio}

O tutor que desempenha esse papel assume a tarefa de melhorar a autoeficácia e o sucesso pessoal do aluno, diminuindo sua dependência e estando "presente" apenas nos momentos em que a tutoria precisa de solução para resolver uma situação específica. Esse apoio também é feito canalizando a reflexão do aluno, o incentivando a realizar um exercício de introspecção sobre sua própria prática.

Esta ênfase na reflexão da formação de professores (Arfelis, 2015) pode ser rastreada até o trabalho de Schön (1992), definindo-a como a capacidade de reformular a prática de acordo com a experiência adquirida ou com os novos conhecimentos que são incorporados. Deles segue-se uma formação de professores baseada na estruturação do conhecimento, a fim de adquirir as habilidades pedagógicas necessárias para a prática 
da profissão. "O sucesso do tutor como conselheiro dependerá de ser capaz de melhorar a capacidade do professor em formação para se conscientizar de seu desempenho prático" (Pérez Abellás et al., 2010, p. 95), ampliando o impacto da formação recebida pelo aluno e aumentando as expectativas dele sobre o seu futuro como profissional de educação.

\section{Como um membro de uma equipe}

O trabalho da tutoria leva implícito realizar ações coordenadas com outros agentes, sejam eles parceiros da instituição onde está ou da Universidade. Isso requer a capacidade de trabalhar como um membro de um grupo, e às vezes para ser o coordenador. Esta é uma competência que, segundo Pérez Abellás et al. (2010) abrange dimensões como a capacidade de comunicação para transmitir informações quando necessário, resolver conflitos e interagir com os tutores universitários e elaborar relatórios precisos de acordo com as regras. É por isso que, para realizar este tipo de papel, é necessário ter um "toque" ou habilidade especial, porque se eles não são desenvolvidos corretamente eles podem gerar conflitos. Há investigações que apontam para esse fato como o segundo em importância para os tutores, por trás de seu próprio sucesso no trabalho docente, sendo chave nos profissionais que mais notoriedade mostram ter, "os professores cooperantes mais desejáveis são aqueles preocupados com as relações humanas democráticas" (Clarke et al., 2014, p. 180). Por sua vez, esses autores indicam como os alunos tratados dessa forma atingem objetivos maiores do que outros.

\section{Como observador}

Como um futuro professor, há uma habilidade que é necessária para a prática da profissão, a observação. Essa habilidade é vital no processo de tutoria de dois pontos de vista diferentes. Como um processo a ser realizado pelo tutor, sobre as ações do próprio aluno para ser capaz de aconselhar e ajudá-lo a melhorar suas habilidades como um professor, e como um processo de reflexão sobre as tarefas que ele desempenha em seu papel como professor de professores. Pode-se verificar que é uma ferramenta da qual se extrai uma grande quantidade de informações e conhecimentos sobre o trabalho docente, tanto do tutor quanto do resto do corpo docente. 


\section{Como um conhecedor do cenário de trabalho}

Devemos partir da concepção da escola como uma organização com estrutura para entender que o tutor deve conhecer e compreender a natureza do que acontece lá, caracterizando-se por uma dimensão formal marcada pela administração, como por uma dimensão dinâmica estabelecida por sua cultura e pessoas, assim falando de um labirinto político e social que forma a comunidade educativa (Zapico, Martínez e Montero, 2017). Portanto, o tutor será capaz de relacionar esses dois aspectos tão relevantes na organização, transmitindo não apenas os aspectos burocráticos, mas as variantes que a profissão adota de acordo com a melhoria trazida pelas pessoas.

\section{Método}

Este estudo está estruturado em torno de seu objetivo geral: pesquisar, identificar e explicar os papéis que os tutores de estágio supervisionado desenvolvem na formação inicial de professores. Esta pesquisa é desenvolvida com uma abordagem qualitativa para a qual a maioria dos autores concorda em descrevê-la com as seguintes características: um tipo de pesquisa humanista, que é a arte, transdisciplinar, com comprometimento ético com a melhoria, criação do conhecimento e com pluralidade metodológica (Bisquerra, 2016). Pode-se dizer que o objeto desse tipo de método é o conhecimento da realidade, fundamentalmente, através do discurso e, em seguida, extraindo as conclusões pertinentes. É preciso compreender esse discurso como o conhecimento que nos foi proporcionado pelos informantes através da palavra ou por escrito sendo, "a linguagem, não apenas um instrumento para investigar a sociedade, mas é o objeto pelo qual se interessa" (Báez e Pérez de Tudela, 2007 p.37) a pesquisa com esta metodologia é desejável quando se quer saber as razões pelas quais os indivíduos agem da maneira que fazem, tanto diariamente como em algum evento particular.

\section{Procedimento, instrumento e amostra.}

Para o presente inquérito foi produzida uma entrevista em profundidade, composta por 30 itens diferenciados em 6 blocos de inquérito sobre: 
biografia do tutor, período de estágio, conhecimentos e habilidades, diploma e grau, a conceituação da profissão de mestre e, por último, de encerramento. Para a seleção da amostra, os professores foram selecionados dentro dos que exercem atualmente sua atividade como tutores de estágio supervisionado dos alunos de graduação. A seleção da amostra baseou-se na disponibilidade de cada um dos tutores para a entrevista. Uma vez solicitada tal colaboração, a entrevista realizou-se com 4 tutores que se voluntariaram para esta finalidade.

Uma vez que se realizou a transcrição, a análise foi realizada através do programa de análise qualitativa ATLAS.ti. Para esta codificação, optouse por um método misto, ou seja, indutivo/dedutivo. Isso é porque entende-se a possibilidade de mudança nos diferentes papéis que assumem os tutores devido a evolução sofrida por esta figura. Portanto, por causa da teoria consultada estabeleceram-se os seguintes códigos: Pract_rol_imitar, Pract_rol_gestor, Pract_rol_apoyo, Pract_rol_equipo e Pract_rol_observador. Além disso, esta pesquisa esteve igualmente aberta para o surgimento de cenários onde o tutor desempenha um outro papel.

\section{Resultados e Discussão}

Esta seção vai começar a dar uma visão geral do que foi encontrado, a fim de esclarecer algumas questões, que se tornam indispensáveis antes de concretizar, mais tarde, cada um dos papéis.

No nível de análise conceitual ${ }^{2}$ percebe-se uma série de recorrências que iam aparecendo ao longo dos textos. E isso deve ser anotado antes de prosseguir com a análise dos códigos. Uma delas foi a vinculação de umas categorias com outras, ou seja, quando um tutor mostrou um certo papel, ele costumava associar-se a outro de forma recorrente, podendo ressaltar que esses papéis eram essenciais entre eles. Graças ao programa ATLAS.ti podemos extrair as associações estabelecidas entre as diferentes categorias (Figura 1) - além da densidade e magnitude dos códigos, que sinalam a relações estabelecidas e a quantidade de citações de cada um dos códigos de forma respectiva - e criar uma rede, podendo destacar na forma concreta o vínculo existente entre três deles, Pract_rol_apoyo, Prat_rol_observador e Pract_rol_gestor.

2 Recordemos que na pesquisa qualitativa com programas deste tipo são definidos dois níveis de análise, um primeiro textual e outro conceitual. 


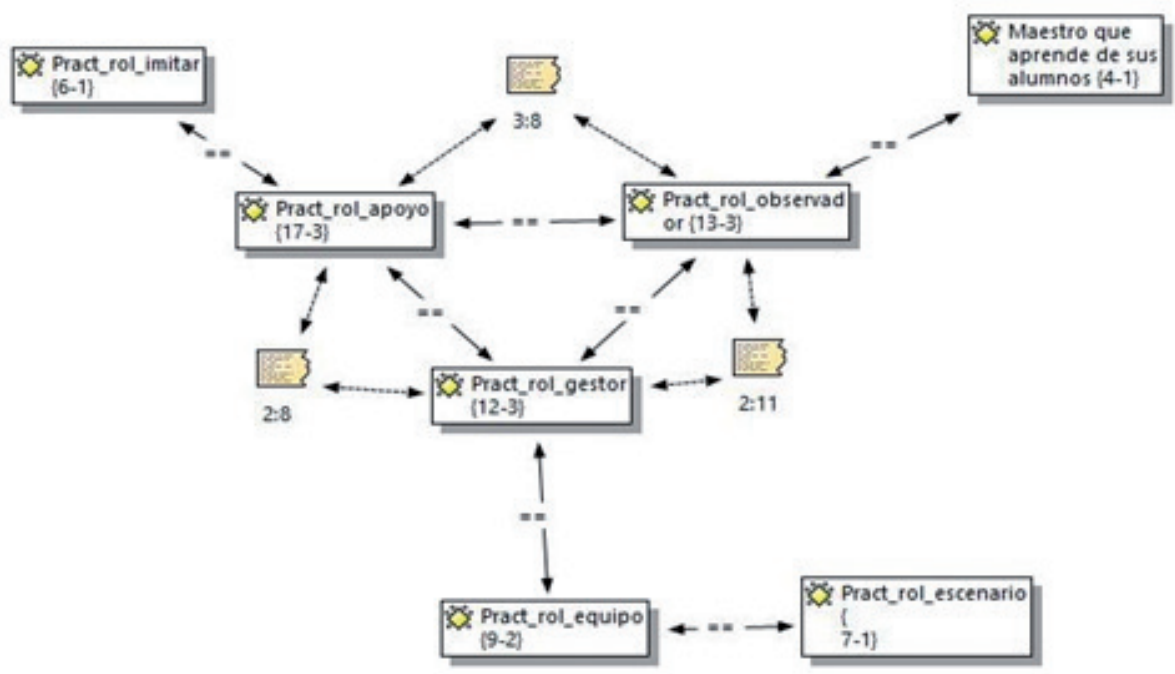

Figura 1: Relação entre papeis dos tutores de estágio.

Como podemos ver, três citações são destacadas em que podemos ver este vínculo. No primeiro deles nos damos conta de como o tutor exerce uma dupla função, de gerente do estágio, procedendo à valorização da permanência no centro, e de conselheiro e apoio do aluno ao buscar a melhoria do processo e do indivíduo.

É uma questão como com os alunos, ou seja, você faz um teste escrito para um aluno, as entregas corrigidas, você dizer-Ihe o que estava errado, por que você colocar essa avaliação, e, portanto, ter um plano de melhoria ou uma possibilidade de... para o professor na prática o mesmo, eu dou-lhe, e digo: "Olha, isto é o que eu vou entregar pelo correio, mas você toma esta cópia e eu coloquei este por este motivo, por esta razão, e minha avaliação é esta." E uma vez que eu dou isso, que já não está condicionado dizendo: "isso eu vou dizer que é muito bom para mim colocar melhor nota", eu pergunto se você tem alguma objeção a fazer uma avaliação pessoal do meu. (P2 2:8 $233: 233)^{3}$

Na segunda, nos encontramos novamente com um papel de gerente de estágio, porque ele volta a falar da questão da avaliação. No entanto, neste caso, podemos destacar sua faceta como observador, pois produz

3 Para fazer a citação das entrevistas facilita-se a oferecida pelo programa ATLAS.ti. Onde é indicado o número do documento e o intervalo de linha em que aparece. 
essa reflexão procurada após o processo de análise da realidade que a rodeia.

Porque chega um momento, e acima de tudo uma avaliação de algo que é subjetivo, ou seja, eu apreciarei o que eu gosto, o estilo literário que eu gosto, o tipo de letra que eu gosto, mas outra pessoa faz outro tipo de avaliação. Então, quando eu vejo se há uma semelhança, eu digo veja, bem, tudo bem, estamos sem margem. Mas quando vejo que há grandes diferenças eu digo: colocamos em questão (P2 2:11 354:354).

Na terceira citação, o processo reflexivo é interpretado novamente desde a observação, uma vez que se refere às idéias recorrentes dos alunos sobre a relação teoria-prática. Podemos também voltar a apontar um modelo de tutor orientador e de apoio, porque se preocupa por compartilhar com seus alunos de estágio a utilidade dos conceitos adquiridos anteriormente.

Para mim uma das coisas que sempre me preocupou como tutora é fazer você ver a importância da teoria de que eles estudam na escola com a prática que, essa é a teoria de que eles estudam na Universidade com a prática que eles aplicam na escola porque é muito frequente que os alunos vêm para a sala de aula e eles dizem Ah, é claro, é que agora você está aqui e tudo o que você estuda na sala de aula não serve para nada, é muito comum que você faça essa reflexão, então é muito importante... (P3 3:8 56:56)

Desta forma, podemos concretizar que em nossa análise de tutores de estágio não se mostra um único modelo de tutor, mas que aparece um papel mais holístico, que tenta entender o estágio como um tempo de apoio ao aluno, enquanto que o tutor exerce o papel de gerente e observador reflexivo da ação do aluno de estágio. De fato, Schön (1992), já apontou como esse processo de supervisão que ocorre é necessário para que se realizem em diferentes planos, os quais concordam com estes três descritos, analisar as situações, sendo o eixo central da prática e podendo se comparar com o modelo de tutor observador; a metanálise, onde o tutor exercerá este trabalho como conselheiro na tarefa do aluno como analista de suas próprias situações; e instrumentalmente e de apoio, desenvolvendo o trabalho de gerente e suporte no processo. Como podemos comprovar através das entrevistas, estes três espectros 
se cruzam durante todo o processo, mas, dependendo dos indivíduos, aluno ou tutor, alguns deles podem prevalecer.

Nas seções a seguir, realizaremos uma análise dos papéis que apareceram de forma mais recorrente, estudando as ideias que surgem de cada um deles, uma vez que estão ligados ao referencial.

\section{Papel de conselheiro e apoio do aluno.}

Como primeiros traços, podemos observar como é um modelo de tutor que entra em jogo ou é combinado com três dos outros tipos, embora já tivesse indicado o vínculo, quase permanente, com o tutor Manager e o tutor observador. Desta forma, a maioria das citações encontradas fazem este modelo relacionar-se com os outros, por isso podemos dizer que isso serve como um eixo central ou pilar para os outros dois que temos apontado no ponto anterior. Embora seja também necessário considerar como este modelo está vinculado com o papel do professor para imitar.

Como havia sido apontado, essa "atitude" que apresenta o professor veterano para o aluno assume a tarefa de melhorar a auto-eficácia e o sucesso pessoal do aluno através da diminuição de sua dependência e estar "presente" apenas nos momentos em que a tutoria precisa ajudar a resolver uma situação específica, canalizando a reflexão do aluno para uma introspecção profunda de suas ações, conhecimento, etc. Uma reflexão que autores como Schön (1992), Barrios, Dios e Rodilla (em Morales Calvo, 2013) e Pérez Abellás, Cid e Sarmiento (2010) apontam como essenciais para compreender e analisar corretamente as situações que surgem no dia a dia da prática Profissional do professor. Esta reflexão serve para esclarecer "situações de prática que são incertas, singulares ou conflitantes" (Schön, 1992, p. 47). Uma reflexão entendida como uma ponte ou veículo entre o desempenho acadêmico e profissional, sendo o tutor uma figura que ajuda o aluno em um processo tão delicado.

Você está bem com o que eu fiz? "ou" você acha que eu estive bem? "ou eu ensinar-Ihes os testes e, em seguida, por exemplo, agora que estamos com... Q: isso ajuda você?

A.: Eu acho que sim. (P1, 1:7 94:98)

Eu também dou como Conselho, como dizer bem, eu vou dizer que eu sou um pouco falante, mas eu acho que há coisas que você deve ter em conta para quando você realmente lutando para a sala de aula. (P4 4:4 32:32) 
Aqui podemos começar a intuir uma das funções fundamentais que o estágio tem na formação dos professores, o que não é nada além de completar e enriquecer esse processo. Compreender este período como um grande momento de crescimento pessoal e reforço ou consolidação, tanto a personalidade do futuro professor e do aluno de estágio supervisionado e seus esquemas mentais em torno da educação

Por outro lado, esse estilo de tutoria também tem um aspecto psicossocial, onde o professor experiente exerce como acompanhante do futuro professor. Neste papel, podemos destacar como emerge o apoio incondicional daquela pessoa que ensina, que compreende o seu trabalho como um processo com grande influência sobre a pessoa que compartilha a sala de aula com ele. Pérez Abellás, Cid, e Sarmiento (2011) já apontaram essa função como uma das que são feitas de forma mais recorrente no desenvolvimento do estágio do Magistério, e nele podemos ver o lado mais humanista deste período, no qual o aluno é encorajado a deixar de ser ele, movendo-se para participar de uma equipe de trabalho, conhecendo o apoio por trás dele.

Eu me preocupo com você, você é importante para mim, você pode contar comigo no que eu posso ajudá-lo (P2 2:9 253:253)

Que eles veem que eles estão na parte do professor, não na parte do aluno, então que precisamos de sua colaboração, porque para o funcionamento correto do dia a dia dentro da sala de aula, as normas, o saber ser, as formas...

(P2 2:3 77:77)

Mas não só será suficiente para alcançar o sucesso, como a prosperidade do tutor como conselheiro e apoio é uma relação considerável com a sua capacidade de melhorar as competências do professor em formação, como o compromisso que este desenvolvimento deve manter uma dupla inclinação, com o aluno e sua formação, que eles também tiveram quando foram formados.

O protótipo do tutor com o qual estamos lidando também tem que fazer (não seria outro verbo?) substancialmente com os motivos que os levam a serem tutores de estágio supervisionado. O desejo de colaborar e de devolver o que um dia Ihes foi dado faz-Ihes parecer com alguma obrigação de atender aos professores novatos que batem à porta. Eles mesmos veem como uma oportunidade para continuarem aprendendo, por meio de treinamento contínuo e de ação que completa 
o treinamento que estes recebem nas faculdades, não apenas como essa ligação teoria-prática já vista, mas como a oportunidade de ser introduzido na tarefa profissional acompanhada, e assim ser capaz de "perder" esse medo que muitas vezes se tem quando se vai sozinho para a sala de aula.

Eu tomo a pessoa da prática e digo: "Olha, você vai fazer isso comigo, isso, o que você precisa? o que...? Eles perguntam-lhe: "queremos ver o projeto curricular, o projeto educativo, o PEC, PCC ou programação", sim, pedimos, pedimos, e então eu vou... se alguém me perguntar com mais seriedade ", e você quer vê-lo juntos? Ou conversamos sobre algo." (P1 1:11 243:243)

Juntos, esses aspectos observados nos lembram a "tutoria clínica" descrita por Martín (1988, em Morales 2013), que destacou a importância do desenvolvimento do aluno e a necessidade de um caráter cooperativo na relação entre tutor e aluno. Tal modelo de mentoring usaria um método consultivo caracterizado pelo aumento da compreensão entre os participantes e sua interação, tentando, assim, utilizar uma abordagem personalizada para aconselhamento individual.

Assim, podemos perceber como o papel de conselheiro e apoio do tutor tem um conjunto de estratégias para influenciar o aluno que podemos resumir em:

- Discussão centrada na prática e articulação com a teoria, tudo com reflexão como um núcleo de ação.

- Apoio pessoal e emocional ao aluno e, assim, alcançar o desenvolvimento integral das competências necessárias no trabalho profissional que se desenvolverá no futuro.

- Experiência como meio de troca de conhecimento e interação entre iguais.

\section{Papel do gerente de Practicum}

A função gerente em um processo deste tipo tem um peso importante em seu desenvolvimento, talvez para ele é um aspecto mais proeminente mencionado pelos tutores durante as entrevistas, de modo que este modelo de tutor é parte do triângulo de papéis que foram destacados neste texto. Ele compartilha muitas coincidências com os outros dois modelos, no entanto, como o anterior foi vinculado a uma quarta categoria, isso 
também está associado em certas nomeações com o tutor como um membro de uma equipe.

Este modelo de tutor começa a aparecer quando no centro de estágio decide-se acomodar os alunos e começa-se a planejar sua distribuição entre todos os professores, participando de seu planejamento, desenvolvimento e avaliação. Deste, uma parte importante é a seleção dos tutores, uma vez que dependerá de que um professor com experiência esteja à vontade com o aluno que tem que introduzir na cultura profissional. Por outro lado, dentro desse planejamento devemos considerar esse momento de introdução em que o aluno chega a um centro, muitas vezes desconhecido, e é necessário criar um clima de confiança.

No (...) quando começamos o curso o chefe de estudos sempre nos diz: "Vamos ver, quem quer alunos?" e então eu sempre digo, "eu faço e os três trimestres". (P1 1:2 25:25)

P.: como você os recebeu?, como eles chegaram?, o que...?

Olha, eles sempre foram feitos, quando chegam os alunos de práticas sempre dar-lhes uma recepção pela direção, ou seja, a primeira coisa que eles fazem, então quando eu era do diretor, porque entrou no meu escritório, foi um tempo conversando com eles, tais, Eu tentei tranquilizá-los um pouco, porque as pessoas chegam muito nervoso, muito nervoso, e então eles são apresentados aos tutores. (P3 3:4 22:24)

Como pode-se ver, no papel de gerente você também tem que incluir aspectos emocionais, como tranquilizar a pessoa que chega, por isso está ligada tão fortemente ao papel de apoio e conselheiro do aluno. Além disso, todos os autores consultados (Martínez E Raposo, 2011; Morales, 2013; Pascual e Nuñez, 2012; Zabalza, 1998, 2013) concordam que a ação que ocorre durante esse período deve ser devidamente estruturada e planejada de acordo com os objetivos e competências a serem cumpridas, não deixando espaço para grandes períodos de improvisação. Esta área exigirá a análise das possíveis necessidades do aluno, definindo os objetivos a serem cumpridos e, dependendo destes, estabelecer um itinerário de desempenhos. Desta forma, podemos sequenciar as diferentes fases do período de estágio e o aluno será dado a reflexão sobre o que ele fez.

No entanto, onde o núcleo de atividade deste agente do estágio é focado está na tarefa de desenvolvimento e valorização. Dessa forma, 
curiosamente só aparecem referências à fase de valorização, o que sugere que é que os tutores entrevistados mais apreciam, ou levam em conta. Apesar disso, no perfil do "tutor ideal" designado por Barrios, Dios e Rodilla (em Zabalza e Cid, 1998) vemos como eles são marcados com aspectos mais importantes relacionados ao desenvolvimento, como fornecer os instrumentos necessários para o aluno, para informá-lo sobre o centro de estágio e sua linha pedagógica ou analisar o trabalho dos alunos dando-lhes responsabilidades progressivamente.

O contato é através do relatório enviado através do aluno, que prontamente o aluno sempre entrega o primeiro dia em que vai, bem, um pouco o que se espera de seu comportamento, sua atitude, e a folha de avaliação que terá que cobrir o professor de tutor para Fim do seu período de estágio. (P2 2:4 86:86) A única coisa que eu cobri é um relatório que eu dou ao chefe de estudos. (P1 1:5 78:78)

Eu até agora a única coisa que me deram são alguns papéis que eu tenho que cobrir com um físico com uma escala de um a cinco e pontuação. (P1 1:6 82:82)

Porque chega um momento, e acima de tudo uma avaliação de algo que é subjetivo, ou seja, eu apreciarei o que eu gosto, o estilo literário que eu gosto, o tipo de letra que eu gosto, mas outra pessoa faz outro tipo de avaliação. Então, quando eu vejo se há uma semelhança, eu digo Hey, bem, Ok, estamos ajustados. Mas quando vejo que há grandes diferenças eu digo: colocamos em questão (P2 2:11 354:354)

Destas citações referidas às avaliações do processo podem ser extraídas duas considerações importantes. A primeira, e mais simples em termos de construção do conhecimento, seria ver a avaliação como ponto e fim de um processo onde o que é feito é uma pontuação em uma escala numérica das ações do aluno. Por outro lado, temos a segunda visão, na qual a avaliação seria um processo em si, graças ao qual poderia fazer uma melhoria nas tarefas e competências do aluno. Teríamos, então, uma avaliação sumativa e outra formativa que, dependendo do que é escolhido, podemos intuir que o resultado afetaria de uma forma diferente o procedimento.

Finalmente, dentro desse aspecto gerencial, encontramos também a relação com os centros dos quais os alunos vêm. Este é um fator de grande importância, dado que o estágio beneficia ambas as instituições, 
tanto a que envia quanto a que recebe, e deve ser cuidado por ambas as partes.

\section{Papel de observador}

Ao longo da literatura que trata com o escopo que estamos lidando podemos destacar um fator comum a partir dele. Vários autores (Cid e Ocampo 2006; Martínez e Raposo, 2011; Morales 2013; ou Zabalza 2013) apontam que a tarefa de observador do tutor de estágio é de vital importância, uma vez que será útil como uma ferramenta do processo reflexivo necessário no estágio. Esta faceta do professor especialista irá atendê-lo, além do processo de reflexão, tanto para aconselhar o aluno sobre o seu desempenho como sendo capaz de sensibilizar a sua atividade e da qualidade do seu trabalho. Além disso, o professor em formação deve aprender através de suas próprias observações, que será modelado pelo tutor.

Este tipo de tutoria assemelha-se ao de "desenvolvimento" exibido por Martín (1988, em Morales 2013), que aponta para o tutor docente como um investigador reflexivo sobre as ações que aconteceram na sala de aula, que é capaz de favorecer o crescimento pessoal de seu aluno. Esta capacidade de examinar professores experientes é estabelecida como um requisito indispensável para a sua tarefa (Pérez Abellás, Cid e Sarmiento, 2010), e deve ser realizado de forma sistemática, a fim de ser capaz de acompanhar o processo estabelecido.

Q: o que te traz?

A.: porque me deu muitos momentos de reflexão sobre o trabalho, que contribuiu para ver também as melhores pessoas que vêm com novas idéias, com..., há tudo, certo?, há tudo, mas bom, fundamentalmente reflexão sobre o trabalho, MIME, cuidado ao fazer coisas (P3 3:2 14:16)

R.:... é muito curioso, porque é outra das coisas que tenho observado muitas vezes nos alunos, que posição?, eu não sei se você observar algo nisso, como ele muda a situação do que eles valorizam quando eles são colocados no ponto de vista do professor. (P3 3:12 128:128)

A partir destas citações segue uma perspectiva do professor observante, a de situar-se "acima" do que o rodeia e examiná-lo de uma forma meticulosa. Esta avaliação do que acontece em seu ambiente 
servirá como ponto de partida para uma reflexão sobre o fato educacional, tanto o processo de aprendizado de seus alunos quanto o ensinamento feito por ele. Além disso, não podemos esquecer que eles apontam esta maneira de "observar as coisas" como uma oportunidade de aprender por si mesmos, graças às novas ideias para o ensino que surgem de seus alunos em práticas e suas reflexões sobre a experiência.

Por outro lado, também indicam como no texto são mostradas as funções que Cid e Ocampo (2006) indicaram como necessário e devem ser executadas pelo tutor, como eles são, avaliar as ações do mestre na prática de acordo com os critérios pré-estabelecidos ou executar uma observação analítica e reflexiva do processo que serve como um ponto de melhoria para o aluno. Desta forma, o professor especialista transmite suas reflexões e estes, que por sua vez, são utilizados como ponto de referência em um processo formativo.

O que não podemos fingir é que eu vou impor e eu vou jogar, sem senhores, vamos observar, haverá coisas que estão lá que são boas e, em seguida, haverá outros que terão de mudar e que teremos de ir mudá-lo, porque aqui é igual, para mim esta menina me deu que, isso significa, e me contou sobre os projetos, se fosse talvez de outra forma e nós estávamos conversando, e discutir essa entrevista, ou seja, que eu vou contribuir com as coisas. (P4 4:14 219:219)

Como você pode ver, temos o tutor observador como um avaliador dos processos que estão ocorrendo na sala de aula. Desta forma, não só você vai refletir sobre o que você vê, não só você vai explorar como as ações acontecem em seu ambiente, mas você será comparado com os padrões de aprendizagem que seus alunos estagiários devem alcançar. Com isso, o professor experiente torna-se um magistrado que deve "questionar" os aspectos suscetíveis a serem avaliados. Também não devemos esquecer a relação humana que se estabelece, o que facilita ao tutor examinar diligentemente, não só as habilidades conceituais ou processuais que o aluno adquiriu ao longo de sua formação inicial, mas também as atitudes que essa ele mostra em suas ações, porque, como devemos lembrar, a concorrência também inclui os valores que a pessoa possui intrinsecamente. 
Q: você tem algum critério para dizer "esta é uma pessoa que vale isso"?

R.: critério, bem, é a observação para ver como ele reage e como ele atua na classe e como eu falo com entusiasmo, eu acho que, eu não sei, quando uma coisa que você gosta e você vive e, você transmiti-lo de alguma forma, isto é, acontece a todos nós em todas as profissões. (P3 3:15 302:304)

\section{Considerações finais}

As modalidades de tutor identificadas iam nos servir para realizar a análise posterior das entrevistas e nelas encontramos um modelo de tutor que não se adequa a apenas um único papel. Assim, conclui-se que os tutores, pelo menos neste estudo, não são definidos por um único papel, mas que seu modo de agir resulta de uma confluência de atitudes e que priorizam funções em sua atividade como docentes. Assim, vimos como um tutor que prioriza o aspecto do planejamento e desenvolvimento do estágio não só desenvolve o papel de gestor, porque ao examiná-lo emergiram outras qualidades e ações que fazem parte de outros papéis.

Assim, vimos o tutor como gerente de um estágio que precisa de um planejamento e correto desenvolvimento e avaliação para que o uso desse período seja o mais enriquecedor possível para o aluno. Ressaltamos também esse tutor observador, que reflete sobre a prática, não apenas para ensinar o professor que está sendo formado, mas como um elemento de auto-aprendizagem através do qual é "atualizado" sobre novas perspectivas, ferramentas, metodologias educativas... e melhora o seu trabalho diário; em suma, poderíamos também referir-nos às oportunidades de desenvolvimento profissionais envolvidas.

Para isso, ainda acrescentava um último papel que enfatizamos em nosso trío, o tutor como apoio e conselheiro do aluno. Este, talvez, pode ser um dos mais importantes a serem tidos em conta, uma vez que, neste caso, uma grande influência é exercida sobre uma pessoa, de modo que o fato de que o professor experiente desenvolveu, ou não, competências para efetivamente exercer esse papel irá marcar a experiência do aluno neste período de treinamento inicial.

Deve-se ressaltar que o tema dos tutores do estágio é uma área de pesquisa e ação com a necessidade de se ter um impulso em seu estudo, e para mostrar a relevância na formação dos professores de alguns indivíduos que atuam como uma ponte entre a formação teórica que os 
futuros professores recebem e a prática que enfrentam na sala de aula. De fato, seria de interesse contemplar aspectos como as vantagens da dedicação a esta tarefa ou a formação que possuem para realizar seu trabalho.

\section{Referências}

Alcalá, D., Garijo, A., e Pueyo, Á. (2017). Una propuesta para la formación inicial del profesorado. Cuadernos de pedagogía, (479), 56-58.

Arfelis, M. (2015). El ApS en el Practicum de la formación inicial del profesorado. RIDAS. Revista iberoamericana de aprendizaje servicio: Solidaridad, ciudadanía y educación, (1), 157-158.

Báez e Pérez de Tudela, J. (2007). Investigación cualitativa. Esic.

Bisquerra, R. (2016). Metodología de la investigación educativa. La Muralla.

Cid, A., e Ocampo Gómez, C. I. (2006). Funciones tutoriales en el Practicum correspondiente al actual plan de estudios de Magisterio en la Universidad de Vigo. Revista de Educación, 340, 307.

Cid, A., Pérez Abellás, A., e Sarmiento, J. (2011). La tutoría en el Practicum: revisión de la literatura. Revista de Educación, (354), 127-154.

Clarke, A., Triggs, V., e Nielsen, W. (2014). Cooperating Teacher Participation in Teacher Education: A Review of the Literature. Review of educational research, 84(2), 163202.

Domingo, J. (2013). El saber de la experiencia en la formación inicial del profesorado. Revista interuniversitaria de formación del profesorado, (78), 125-136.

Escudero, J. M., Cutanda, T., e Trillo o, F. (2017). Aprendizaje docente y desarrollo profesional del profesorado. Profesorado, 21(3), 83-102.

Esteve, M. (2006). La profesión docente en Europa: perfil, tendencias y problemática: La formación inicial: [Comentarios a los Informes EURYDICE y OCDE sobre la cuestión docente]. Revista de Educación, (340), 19-40.

Gutiérrez, E., Fernández, R., e Rodríguez, M. (2014). La formación inicial del profesorado en el «habitus» capitalista. Cuadernos de pedagogía, (445), 75-78.

Hevia, I., e González Riaño, A. (2012). El Practicum de los estudios universitarios de pedagogía: visión y aportaciones de los tutores. Revista Iberoamericana de Educación, 59(2).

Imbernón, F., e Sabaté, J. (2018). Formación inicial del profesorado... ¿Qué le falta? Aula de secundaria, (29), 31-35.

Marchesi, A. y Pérez, E. (2004). La situación profesional de los docentes. Instituto de Evaluación y Asesoramiento Educativo. Disponible en: http: www.fuhem.es

Martínez Figueira, E., e Raposo, M. (2011). Funciones generales de la tutoría en el Practicum: entre la realidad y el deseo en el desempeño de la acción tutorial. Revista de Educación, (354), 155-181.

Montero, L. (2002). La formación inicial: ¿puerta de entrada al desarrollo profesional? Educar, (30), 69-89. 
Montero, L. (2018). Relaciones entre teoría y práctica en la formación inicial. Percepciones de formadores y estudiantes del Grado de Maestro en Educación primaria. Educatio siglo XXI: Revista de la Facultad de Educación, 36(2), 303-330.

Montero, L., e Gewerc, A. (2018). La profesión docente en la sociedad del conocimiento: Una mirada a través de la revisión de investigaciones de los últimos 10 años. RED: Revista de Educación a Distancia, (56), 3.

Morales, S. (Ed.). (2013). El practicum como experiencia de aprendizaje en educación social: propuestas para su desarrollo: planificación, tutoría docente y proyección social. Editorial Universitas.

Pascual, I., e Núñez del Río, M. (2012). La colaboración de los tutores de centros en la evaluación de competencias en el Prácticum. Revista Española de Orientación y Psicopedagogía, 23.

Pérez Abellás, A., Cid, A., e Sarmiento, J. (2010). La Tutoría en el practicum: aportaciones de los symposios de Poio. Andavira Editora.

Schön, D. A. (1992). La Formación de profesionales reflexivos: hacia un nuevo diseño de la enseñanza y el aprendizaje en las profesiones. Paidós.

Valliant, D. e Marcelo, C. (2015). El ABC y D de la Formación Docente. Narcea

Marcelo, C., e Vaillant, D. (2009). Desarrollo profesional docente: cómo se aprende a enseñar. Narcea.

Zabalza, M. A. (2013). El practicum y las prácticas en empresas: En la formación universitaria. Narcea.

Zabalza, M., Cid, J. (Eds.). (1998). Los Tutores en el practicum: funciones, formación, compromiso institucional: actas del IV Symposium de Prácticas celebrado en Poio, 13-15 junio 1996. Diputación de Pontevedra.

Zapico, M., Martínez, E., e Montero, M. (2017). Demandas sociales y formación inicial del profesorado: ¿un callejón sin salida? Profesorado, 21(1), 80-102. 
